\title{
WHAT IS THE EPISTEMIC SIGNIFICANCE OF DISAGREEMENT?
}

\author{
N. Gabriel MARTIN
}

\begin{abstract}
Over the past decade, attention to epistemically significant disagreement has centered on the question of whose disagreement qualifies as significant, but ignored another fundamental question: what is the epistemic significance of disagreement? While epistemologists have assumed that disagreement is only significant when it indicates a determinate likelihood that one's own belief is false, and therefore that only disagreements with epistemic peers are significant at all, they have ignored a more subtle and more basic significance that belongs to all disagreements, regardless of who they are with-that the opposing party is wrong. It is important to recognize the basic significance of disagreement since it is what explains all manners of rational responses to disagreement, including assessing possible epistemic peers and arguing against opponents regardless of their epistemic fitness.
\end{abstract}

KEYWORDS: social epistemology, disagreement, epistemic peers

In epistemology over the past decade a lively discussion about disagreement has focussed on the conditions under which disagreement becomes epistemically significant. This dispute ignores the more basic question-what significance can or does disagreement have?

Although this basic question has not been explored in the literature, the way that the literature asks its own question presupposes an answer. In this article I will raise the question of whether the significance of disagreement presupposed by the epistemology of disagreement really is the significance disagreement has. I will argue that the significance presupposed throughout the sub-field-that disagreement qualifies the likelihood of the falsity of one's own belief-is not its most general or basic. Disagreement's significance does not concern oneself but rather one's opponent. It is that the person with whom one disagrees is wrong.

I will defend this claim and explain why it matters. First, I will explain how the discussion of the epistemological consequences of disagreement presuppose what I will call a self-reflexive significance. This will allow me, in section two, to show why this significance cannot belong generally to all disagreements, but can only belong to disagreements when they possess certain qualifying characteristics. That will in turn make it possible, in section three, to settle a current debate 


\section{N. Gabriel Martin}

within the sub-field concerning whether the peerhood of interlocutors is to be presupposed. Disagreement only possesses this significance conditionally, and it is only when it has been determined to meet certain conditions that it can be considered significant. This raises the crucial question-what reason is there to evaluate disagreements on the basis of peerhood? There must be some basic and general significance belonging to disagreement as such that makes evaluating opponents make sense. I will address this question in section four. Finally, in section five, I will explain why this matters - the epistemological significance of disagreement is not simply what it indicates about your own belief, but what it indicates about the beliefs of others. This means that the epistemic significance of disagreement is fundamentally social and intersubjective.

\section{Disagreement's Self-Reflexive Significance}

Let me restate the question: what significance can or does disagreement have? An answer to this question would have to disclose the significance of disagreement itself-whether disagreement on some matter, in and of itself, has any bearing on that matter. Put another way, the question is whether any light can be shed on that which we disagree about (the disputandum) by the very fact that we disagree about it. The strictly epistemic question is insensitive to the many additional questions about the context of the disagreement, including the psychology of its participants or their social relations, that could be raised. Doubtless, dispute tells us something about the attitudes of the people involved, and controversy tells us something about the culture in which it exists, but the epistemology of disagreement sets these matters asides. It is concerned narrowly with whether the mere fact that there is a disagreement can indicate something about the disputandum, either directly or indirectly.

The question of the significance of disagreement also excludes questions about the significance of the positions in conflict themselves. Of course a disagreement consists of positions, hopefully supported by reasons and evidence, which bear upon the disputed matter in all sorts of relevant ways. This is not what epistemology of disagreement is concerned with either. The epistemic significance of disagreement itself is not due to the significance of those positions or what supports them: it is due solely to the significance of the fact that the matter is in dispute.

It has been proposed that the epistemic significance of disagreement, defined in such a narrow way, is profound. Disagreement may bring with it sceptical 
consequences if it can indicate an increased likelihood of error on one's own part. ${ }^{1}$ This view is shared by many within the sub-field. ${ }^{2}$ If disagreement can indicate, either generally or under certain circumstances, that there is considerable chance that you have formed an incorrect belief, then diminished confidence in your position is warranted. This is the way that the problem of disagreement was originally framed by Sextus Empiricus. ${ }^{3}$

Most contributors to the literature are in agreement that the appropriate response to epistemically significant disagreement is to become less confident in the correctness of one's own position. ${ }^{4}$ That is, there is a consensus among most social epistemologists that faced with a disagreement of epistemic significance a person should check the confidence with which they hold their controversial position. That diminished confidence is the appropriate response to any disagreement which possesses epistemic significance is rarely disputed. ${ }^{5}$ Instead,

${ }^{1}$ As considered here, the problem of disagreement only arises for those involved-it is not a question of what disagreement means for one who occupies a neutral position, but what disagreement means when you are one of the parties embroiled in it.

2 For example, see Adam Elga, "Reflection and Disagreement," Noûs 41, 3 (2007): 497; Robert Mark Simpson, "Epistemic Peerhood and the Epistemology of Disagreement," Philosophical Studies 164, 2 (2013): 561-577; Ernest Sosa, "The Epistemology of Disagreement," in Social Epistemology, ed. Adrian Haddock, Alan Millar and Duncan Pritchard (Oxford: Oxford University Press, 2010), 278-297. Others disagree. According to Thomas Kelly, "The Epistemic Significance of Disagreement," in Oxford Studies in Epistemology, Volume 1, ed. John Hawthorne and Tamar Gendler (Oxford: Oxford University Press. 2005), 191, diminished confidence in the correctness of one's own position should not be the consequence of any disagreement, but that is because he denies that there are any epistemically significant disagreements.

${ }^{3}$ Sextus Empiricus, Outlines of Scepticism, trans. Julia Annas, and Jonathan Barnes (New York: Cambridge University Press, 1994), 41.

${ }^{4}$ See especially Adam Elga, "Reflection and Disagreement," 497. There is, however, no obligation to diminish confidence according to those who deny the claim that there is a unique rational doxastic response to any body of evidence (See Nathan Ballantyne, E.J. Coffman, "Uniqueness, Evidence, and Rationality," Philosophers' Imprint 11, 18 [2011]: 1-13; Roger White, "Epistemic Permissiveness," Philosophical Perspectives 19, 1 [2005]: 445-459). However if permissiveness should apply to two conflicting theories, it does not seem appropriate to call this a disagreement, since while the two theories conflict they do not invalidate one another.

${ }^{5}$ An exception is Gurpreet Rattan "Disagreement and the First-Person Perspective," Analytic Philosophy 55, 1 (2014): 331-353. Rattan argues that disagreement between epistemic peers indicates that there is a misunderstanding or equivocation at work, and that "the epistemic limits of intersubjective understanding" (Rattan, "Disagreement and the First-Person Perspective," 351) justify what he calls "limited permission to persist in confidence" (Rattan, "Disagreement and the First-Person Perspective," 350) until the matter is cleared up. 


\section{N. Gabriel Martin}

the debate is over whether there exist any disagreements which in and of themselves call for that response. ${ }^{6}$

I will ask a different question. Disagreement that has sceptical consequences for a reasonable participant must have a certain kind of significance. My question is: what kind of significance is it that would call for diminished confidence?

\section{Self-Reflexive Significance Is Limited to Only Some Disagreements}

For starters, this shows that the significance of disagreement is conceived in a strictly negative way-its significance is in indicating (in some way we have not determined yet) that beliefs about the matter are wrong. There are no other possibilities given that what we are considering is in no case direct or first-order evidence about the disputandum, but second-order evidence. It therefore pertains to the disputandum indirectly, by giving evidence about the truth or falsity of the beliefs about the disputandum itself. As such, all it can do is undercut the confidence with which a belief is held.

The simple possibility of error cannot be what calls for doubt in the face of disagreement. It is possible for your belief to be in error, but it is the fallibility of the belief itself which signifies this, and a disagreement can only be a reminder of the possibility of error if it is already acknowledged. If disagreement can tell you anything more about the possibility that you are wrong in a given case, it is because it is already a characteristic of your belief that it may not be right. The possibility of being wrong is a precondition for a fact to provide evidence that you are wrong-without the possibility of error, facts surrounding your belief could never have anything to do with the possibility that you could be wrong.

Disagreement must tell you something about the possibility that your belief is false if it calls for you to be less confident in your position. Only an indication concerning the likelihood that your belief is wrong can give you any reason to doubt it. The significance of disagreement must indicate something about the

6 See David Christensen, "Epistemology of Disagreement: The Good News," Philosophical Review 116, 2 (2007): 187-217; David Christensen, "Disagreement as Evidence: The Epistemology of Controversy," Philosophy Compass 4, 5 (2009): 756-767; Richard Foley, Intellectual Trust in Oneself and Others (New York: Cambridge University Press, 2001); Ernest Sosa, "The Epistemology of Disagreement," in Social Epistemology, eds. Alan Millar and Duncan Pritchard Adrian Haddock (Oxford: Oxford University Press, 2010), 278-97.. In "Disagreement as Evidence," David Christensen characterises this as a debate between what he calls 'conciliatory' and 'steadfast' views. That is, between interpretations of the significance of disagreement which hold that the rational response is to move closer, in some way or another, to the views of your interlocutor, and interpretations that hold that, in the face of disagreement, you are obligated to retain the confidence in your beliefs that you had going in. 
likelihood of error if it is to warrant diminished confidence, because it is only if it qualifies the already certain possibility of error that it tells you something new.

This response must be justified by additional information about the likelihood that your belief is in error. That is to say, more must be determined about the quality or character of the disagreement. Only disagreement of a particular character can have the kind of significance which would call for you to lose even some confidence in your belief. But can disagreement of a certain type indicate the likelihood that one is in error? ${ }^{7}$

The insignificance of unqualified disagreement is the reason that the epistemology of disagreement is only concerned with qualified disagreement. It is only the disagreement of peers or superiors, which is to say those who are at least as likely as oneself to have knowledge of the matter in dispute, that is meaningful.

Peerhood, or the relative epistemic fitness of those with whom one finds oneself in dispute, is a handy way to indicate what kind of qualification of a disagreement would have the epistemic significance that we are talking about. ${ }^{8}$ If I know that my opponent is as likely as I am to be right about the disputandum, then I also know that the likelihood of error on my own part is high; at least 50 per cent. ${ }^{9}$

The qualification of a given disagreement as a peer disagreement distinguishes it considerably from disagreement in general. The possibility that any one of my beliefs could be false is not determinate in any way (I cannot ascribe any statistical or comparative character to it), but a disagreement between peers is qualitatively determinate. Peer disagreement carries a significance that pertains to the likelihood of error in my position; it indicates that I am no more likely to be right than the person who challenges me. This does not mean that in a peer disagreement I am more likely to be wrong than in any other, unqualified disagreement - it means that in a peer disagreement the likelihood that I am wrong is certain, whereas in the other it is totally indeterminate.

7 That it is by way of indicating an increased likelihood of error that a disagreement could indicate the need to revise one's confidence is assumed generally in the sub field. Christensen gets closest to explicitly stating it when he remarks "arbitrating the dispute from one's own perspective need not entail disregarding evidence that one might be wrong" (Christensen, "Epistemology of Disagreement," 762). It is assumed here by Christensen that 'evidence that one might be wrong' is precisely what is in question.

${ }^{8}$ See Bryan Frances, Disagreement (Cambridge: Polity, 2014), $45 \mathrm{ff}$ for what he calls 'likelihood definitions' of peerhood.

${ }^{9}$ Of course, this conclusion is disputed. However, there is broad consensus that a conclusion along these lines follows from disagreement among true peers. More controversy centres around the likelihood or possibility of finding such peers. 


\section{N. Gabriel Martin}

Since a peer disagreement is defined by the fact that the likelihood that I am wrong and the likelihood that my opponent is wrong are on par with one another, the response that social epistemologists generally believe peer disagreement calls for-diminished confidence-is justified. When I already know that I could be wrong, the fact that I disagree with one of my peers tells me that there is a good chance that I actually am wrong. Once again, we can compare this to disagreement of an unqualified kind, which tells me nothing about the relationship of this instance to that invariant possibility.

Is this the significance of disagreement - that it can inform me about the likelihood that I am in error? That is the consensus in the sub-field, and it is why most of the discussion concerns the conditions under which an opponent can and must be considered one's peer. In the section that follows, I will briefly explain some of the key positions in this debate. As I explain, a key determinant as to whether the disagreements we find ourselves in can be expected to show themselves to be peer disagreements comes down to whether or not peerhood can be thought to be assumed by default, or whether it must be demonstrated. I argue that it must be demonstrated, and that this points to the existence of a more basic and general significance of disagreement.

\section{Peerhood Cannot Be Assumed}

Is it the case that disagreement itself is enough to disqualify an adversary from peerhood with respect to the matter, as Thomas Kelly and Ernest Sosa argue? ${ }^{10}$ Can you consider your opponent less likely than you are to be right, simply on the basis of their being your opponent, or having beliefs which you believe to be wrong? It would seem to follow from your having a belief that anyone who rejected that belief was in your lights far less likely to have knowledge of the matter.

Or, is it necessary to assess your interlocutors on grounds that are independent of the reasoning supporting the position that brings you into conflict, as David Christensen claims? ${ }^{11}$ He argues that, in order to avoid begging the question against your interlocutors, assessment must be on grounds other than that which is at issue in the disagreement in question.

Even if independent grounds for dismissing an adversary as sub-par are required, in real-world controversies are peers likely to be thin on the ground, as

\footnotetext{
${ }^{10}$ See Kelly, "The Epistemic Significance of Disagreement," 2005 and Sosa, "The Epistemology of Disagreement," 2010.

${ }^{11}$ Christensen, "Epistemology of Disagreeement," 2007.
} 
What is the Epistemic Significance of Disagreement?

Adam Elga argues, ${ }^{12}$ because the basis on which to assess the likelihood of being right of those who do not share your views is lacking?

Elga makes the latter claim because our disagreements about controversial questions are generally not anomalies. Rather, disagreements arise within polarised and polarising "clusters of controversy" 13 and when those with whom you disagree on one thing tend to disagree with you on all or most related questions as well, you are not going to find the means to assess their level of expertise in that general area.

All of the conceptions of interlocutor assessment discussed here in brief concern how peerhood or non-peerhood is to be determined. What none of these considerations take into account is whether or not interlocutors must be considered peers by default or whether peerhood must be earned. However, this question is, if not decisive, at least of great significance with respect to the determination. This is because, as Elga points out, assessment will often be impossible to accomplish and therefore the question of whether or not a particular interlocutor is one's peer will come down to whether or not they must be considered one prior to assessment. This question has become the focus of some more recent attention in the sub-field.

Peerhood cannot be a default. That is because it means that you are no more likely to be right than you are to be wrong. Not just any disagreement can have that significance, nor can just any adversary be considered peer. This is not because a peer disagreement necessarily means that your likelihood of being wrong is higher than it is in a disagreement with an unqualified interlocutor. It isn't. The relative likelihood that you are wrong in an unqualified disagreement is uncertain, so it may be higher or lower or identical to that in a peer disagreement. Peerhood cannot be a default precisely because it denotes demonstration of the relative likelihood of the possibility that yours is the position that is wrong in the dispute. It is only once your opponent has been found to be at least as likely as yourself to be right about the matter that their disagreement has the kind of significance concerned: the ability to "say" something about the likelihood of error in your own position. Without a demonstration of the relative likelihood of your opponent's being right, the fact that a true disagreement means that one or the other of you must be wrong does not in any way qualify the general, indeterminate possibility that you could be wrong that you must acknowledge from the start.

Peerhood only means something if it denotes specific characteristics of the interlocutor in question. Therefore it cannot be assumed. This means that the

\footnotetext{
12 Elga, "Reflection and Disagreement," 2007.

${ }^{13}$ Elga, "Reflection and Disagreement," 2007, 493.
} 


\section{N. Gabriel Martin}

assessment of interlocutors and discrimination between those that are peers and those that are not peers is crucial to appreciating the significance of disagreement, and if this assessment is not or cannot be performed then the disagreement cannot be considered 'peer'.

There are a few epistemologists who argue otherwise. ${ }^{14}$ Contesting Elga's conclusion about controversy clusters, Robert Mark Simpson states that "remaining steadfast in the face of a disagreement is only justified when one has some basis for thinking that one's opponents are epistemically less well-credentialed than oneself with respect to the subject of the disagreement."15 In other words, one must have a reason for considering an opponent sub-par. Peerhood, Simpson assumes, is the default.

In arguing against Elga from the assumption of default peerhood, Simpson also reveals that Elga's argument is based on the contrary assumption-that peerhood must be demonstrated. 'Clusters of controversy' refers to the tendency of those with whom one disagrees about serious, real-world issues to also have conflicting views, by and large, about other, related matters. The consequence of these controversy clusters is that we can expect finding real disagreements with someone who can be deemed a peer to be rare. This is because determining that a particular interlocutor is an epistemic peer with respect to a particular matter is only possible after assessing their ability to get such things right. However, because controversies tend not to exist in isolation but in clusters, it is likely that when you disagree with someone on one question you will also disagree with them on related questions and so you will lack the kind of evidence of their being right (by your own lights) on the relevant sorts of questions necessary to establish their peerhood. The way that disagreements form in society makes it improbable for peerhood to be attributed to an opponent in a disagreement.

The example offered by Elga is a disagreement about the ethics of abortion. ${ }^{16}$ Elga supposes that we should expect two people who disagree about abortion also to disagree about related controversies, such as political affiliation, religion, and the definitions of life and personhood. The broad disagreement between the two means they lack any basis on which to establish the other's peer bona fides. This

${ }^{14}$ See Catherine Z. Elgin, Considered Judgment (Princeton: Princeton University Press, 1996); Richard Feldman, "Epistemological Puzzles about Disagreement," Epistemology Futures, ed. Stephen Hetherington (New York: Oxford University Press, 2006): 216-236; Robert Mark Simpson, "Epistemic Peerhood and the Epistemology of Disagreement," Philosophical Studies 164, 2 (2013): 561-577; Ben Sherman, "Unconfirmed Peers and Spinelessness," Canadian Journal of Philosophy 45, 4 (2015): 425-444.

${ }^{15}$ Simpson, "Epistemic Peerhood and the Epistemology of Disagreement," 576.

${ }^{16}$ Elga, "Reflection and Disagreement," 493. 
means that each party will lack any basis on which to perform the required assessment of the epistemic capacity of their interlocutor. Essentially, Elga argues that if an opponent in a disagreement is going to qualify as one's peer, their capacity to get the matter right must be demonstrated. And what is needed in order to demonstrate it is the possibility of pointing to the correctness of their views on related matters.

Rather than taking on Elga's factual claim that real-world disagreements exist within clusters of controversy, as Sarah McGrath and others do, ${ }^{17}$ Simpson disputes Elga's views on what we are to make of the disagreements of those we cannot assess. Elga, we saw, takes the lack of any basis on which to establish an opponent's credentials as sufficient grounds for their dismissal as sub-par. This makes sense because of his assumption that others are not to be considered one's epistemic peers by default; that instead they must earn the right to be considered peers.

Simpson, on the other hand, claims that one must consider a disputant one's epistemic peer until one has evidence that they are not. Thus, the phenomenon of controversy clusters Elga will have a consequence opposite to that attributed to it by Elga.

This difference in the epistemologies of disagreement of Elga and Simpson does not belong to the more frequently raised debate about that basis on which peerhood can be assessed, it is about whether assessment is necessary in the first place, and what happens if it cannot be performed. Although this only appears as an explicit theme in epistemology of disagreement in Ben Sherman (even Elga and Simpson do not make the importance of the question explicit), ${ }^{18}$ it determines for the most part whether or not peer disagreements, with the serious consequences

17 In "Moral Disagreement and Moral Expertise," Oxford Studies In Metaethics, Vol. 3, ed. Russ Shafer-Landau (Oxford: Oxford University Press, 2008): 87-108, Sarah McGrath argues that while controversies do cluster, these clusters form upon common ground sufficient to allow for the assessment of opponents.

${ }^{18}$ In "Unconfirmed Peers and Spinelessness" Sherman brings attention to the role played by the decisive difference between what he calls "presumption of peerhood" and "presumption in favour of self-trust" (Sherman, "Unconfirmed Peers and Spinelessness," 430). Shortly, I will explain how the problematic of presumption of peerhood differs from the problem of default peerhood. Whether or not a given theory of disagreement has it that others are to be considered peer by default plays an enormous role in determining whether peers, as that theory defines them, will be such as can be expected to be found. His answer to the question (See Sherman, "Unconfirmed Peers and Spinelessness," 433-434) supports the complaints of Christensen and Simpson that to discount an adversary without adequate evidence of their epistemic inferiority is "question-begging" (See Christensen, "Epistemology of Disagreement," 198 and Simpson, "Epistemic Peerhood and the Epistemology of Disagreement," 575-576). 


\section{N. Gabriel Martin}

for doxastic confidence they bring with them, are likely to characterise the important controversies that dominate philosophy and the broader culture.

The conflicting assumptions, implicit for the most part, about whether or not peerhood can be presupposed, are applicable in the kind of case considered by Elga, McGrath, and Simpson, in which what is at issue is what it is rational to believe about your interlocutor's epistemic abilities in the absence of conclusive evidence one way or the other. Simpson's opposition to what Sherman calls the "presumption in favour of self-trust"19 is motivated by the concern that to discount an adversary without adequate evidence of their epistemic inferiority is "questionbegging" or "bootstrapping." 20 Foley defends the presumption on the basis that a general prima facie trust in oneself is necessary for any knowledge at all. ${ }^{21}$

Along the same lines, Sherman argues that there should be a "presumption of peerhood."22 Discussing whether disagreement should come with a "presumption in favour of self-trust" as Foley argues, ${ }^{23}$ or a "presumption of peerhood", Sherman argues that the right to legitimately dismiss an opponent as sub-par must be 'earned'. Sherman calls this "earning a spine” in reference to Elga's concern about "spinelessness" as a consequence of peer disagreement. ${ }^{24}$ Spinelessness is Elga's pejorative expression for accepting diminished confidence in the face of disagreement. Sherman's point is that spinelessness can be overcome, but not without work. In other words, peerhood must be presupposed.

Foley defends the presumption in favour of self-trust on the basis that the presupposition of a general prima facie trust in oneself is necessary for any

${ }^{19}$ Sherman, "Unconfirmed Peers and Spinelessness," 430.

${ }^{20}$ See Christensen, "Epistemology of Disagreement," 198; Simpson, "Epistemic Peerhood and the Epistemology of Disagreement," 575-576; Sherman, "Unconfirmed Peers and Spinelessness," 433-434.

${ }^{21}$ Richard Foley, Intellectual Trust in Oneself and Others (New York: Cambridge University Press, 2001), 108.

22 Sherman, "Unconfirmed Peers and Spinelessness," 430.

${ }^{23}$ Foley defends the presumption in favour of self-trust on the basis that the presupposition of a general prima facie trust in oneself is necessary for any knowledge at all (See Foley, Intellectual Trust in Oneself and Others, 108). Self-trust is epistemically essential: even the decision to trust another is only possible because of a more fundamental trust in one's own judgment that that trust is warranted. But just because there is always self-trust involved in any judgment, that does not mean that one is compelled to prefer one's own judgments, reconsidered, over another's. When one reconsiders one's position in the way that is necessary in order to consider a disagreement, it is necessary to trust in the judgment being performed at the moment, but there is no epistemic necessity to trust the previous judgement just because it had been made by the same person, let alone prefer it to the judgment of an interlocutor.

${ }^{24}$ Sherman, "Unconfirmed Peers and Spinelessness," 431. 
What is the Epistemic Significance of Disagreement?

knowledge at all. ${ }^{25}$ Self-trust is epistemically essential: even trust in another is only possible because of a more fundamental trust in one's own judgment that they are to be trusted.

This does not mean, however, that one is compelled to prefer one's own judgments over another's. When reconsidering one's position in order to assess the significance that may or may not be presented by a disagreement it is necessary to trust in the judgment one is utilising at the moment. This does not mean that one is obligated to trust one's previous judgement just because it happened to have been made by oneself, since it is not the judgment being relied upon at the moment. The fact that you are the same person who made the judgment that you must decide whether or not to prefer to that of your interlocutor does not preclude you from changing your mind and siding with them, because although the judgment was made by you it is a distinct act of judgment from the one which you are employing at present. Therefore, there is no obligation to trust it.

Simpson and Sherman raise the important question of whether or not one's adversaries must be assumed to be peers, or whether they can only be thought to be peers when positive evidence of their peerhood has been brought to bear. However, they approach the question from the wrong direction. What matters with respect to whether or not adversaries are to be considered peers by default is not what is rational to believe about the epistemic ability of those with whom we find ourselves in disagreement, but what the conditions are for finding disagreements in which we are involved to be epistemically significant. In this regard there can be no doubt, self-reflexive epistemic significance belongs to disagreements only on the condition that those disagreements are qualified by the peer condition or some similar factor which cannot be granted universally by default.

It is not because of an epistemic principle, either that commanding self-trust or that proscribing question-begging, that peerhood cannot be presupposed. Peerhood cannot be presupposed because it stipulates a quality that distinguishes it from just any disagreement. It is only when peerhood names a quality that makes it possible to determine that the likelihood that one's opponent in a disagreement is wrong is no higher than the likelihood that one is wrong oneself that peerhood can fulfil its essential function of distinguishing the class of disagreement that belongs to it from disagreement in general. If peerhood is presupposed, then it does not contain the crucial qualifying character that it is supposed to. If peerhood is default, then a peer disagreement no longer has the significance it is meant to

${ }^{25}$ Foley, Intellectual Trust in Oneself and Others, 108. 


\section{N. Gabriel Martin}

have-indicating the likelihood of error on one's own part. Default peerhood, therefore, is a meaningless notion.

As long as disagreement is going to have any consequence involving diminished confidence in one's own position, it will be necessary for some characteristic of the disagreement to contribute information about the likelihood of an error on one's own part. If the characteristic in question is not the peerhood of one's opponent, it must be some other qualifying characteristic.

The quality of peerhood only makes sense if the difference between peer and non-peer is enforced. If everyone is your peer by default, then peerhood is not dependent upon evaluation. This equality of all speakers could not be called peerhood, which denotes a class, and it could not signify equality with respect to the likelihood of being right of you and your interlocutor. Only peerhood ascertained through assessment can denote equal likelihood of being right, while general equality of all speakers, which is a presupposition or a principle that is not given in evidence, can only denote that the relative likelihood of being right is indeterminate. If disagreement means only that you cannot know whether or not you are more or less or just as likely as your interlocutor to be right about the disputandum (which seems to me to be the correct interpretation of the meaning of disagreement according to Sextus) it does not bring with it the self-reflexive epistemic significance that calls for diminished confidence.

\section{The Intersubjective Significance of Disagreement}

In section one, I established that if the reasonable response to disagreement is reduction in the confidence one places in one's own position, then the significance of disagreement must pertain to the likelihood that that position is in error. I also argued, in section two, that disagreement in general has no bearing on the probability of error - that in order for disagreement to indicate the likelihood of error, particular qualities belonging to a given disagreement or class of disagreements must indicate its likelihood. Consequently, peerhood cannot be the default for disagreement, as I argued in section three. As long as disagreement is going to have any consequence involving diminished confidence in one's own position, it will be necessary for some characteristic of the disagreement to contribute information about the likelihood of an error on one's own part. If the characteristic in question is not the peerhood of one's opponent, it must be some other qualifying characteristic.

That disagreement cannot call for diminished confidence until investigation has shown that one's opponent is the kind whose disagreement can indicate even odds of error in either position (or until something else has contributed 
What is the Epistemic Significance of Disagreement?

comparatively relevant significance) gives rise to a surprising corollary. The necessity of assessment also means that the significance of disagreement which calls for diminished confidence cannot be the most basic significance of disagreement. If the significance of disagreement is such as would call for diminished confidence, then that significance does not belong to all disagreements by default. This raises the question: what significance does disagreement have already? What calls for the investigation to determine when disagreement calls for diminished confidence, and when it does not.

The assessment necessary for any diminishment of confidence must itself be called for. Why would we ever assess the epistemic ability of our opponent in a disagreement? If disagreement is without significance until assessment has been carried out, then why would anyone ever take the trouble to carry out an assessment? It is only when something grabs our attention that we pay it any mind, let alone investigate it. Since it is taken for granted by everyone that assessing those with whom one is in disagreement makes sense, it must be the case that something about being in disagreement with another grabs our attention. In other words-disagreement is significant.

Evaluation is only rational in case there is a more fundamental significance of disagreement that is not dependent upon peerhood. There must be a more basic significance, belonging to any disagreement whatsoever, that motivates the evaluation of opponents in the first place. A basic significance of disagreement must provide the impetus for the curiosity that drives investigation into the matter.

If, as social epistemologists claim, disagreement with an opponent of a certain character (an expert or a peer) can possess altogether different significance, that significance can only be attached to the disagreement after an assessment of the opponent's relative epistemic fitness has been undertaken; an activity which no one would have any reason to engage in if there was not already some significance which called for it. Paradoxical though it may seem, the significance of peer disagreement - that one should be concerned about being in error oneself-is only possible because of (and as a correction to) the prior significance that one's opposition is in error.

Does disagreement possess this more fundamental kind of significance? Does it possess a significance which is relevant to knowledge of the object of the dispute in question, yet which does not rely on evaluation of one's opponents or, indeed, which does not hinge on any further particular qualities of that dispute? Does disagreement possess a kind of significance just in virtue of being disagreement? If so, what would that significance be? 


\section{N. Gabriel Martin}

Epistemology of disagreement has treated disagreement which is not qualified according to the peer condition as insignificant because it has not recognised any quality that belongs to disagreement in general which differentiates it from the merely possible disagreement which could attach to any belief. As long as actual unqualified disagreement is not distinguished from merely possible disagreement, or the mere possibility of there being a view that conflicts with your own, there is nothing about it to attract your attention. Only if the fact that someone happens to champion one of the indefinite number of possible positions that contradict one of your own can be differentiated from the mere possibility that such a position might be held, can an epistemic significance which belongs to disagreement as such be discerned. Only if it is shown that the significance of the fact that there is a person confronting you with an opposing point of view cannot be reduced to the significance of the reasons that might be produced to support that view can a general significance of disagreement be said to exist.

There is such a significance. Actual disagreement has a significance that is not reducible either to the significance of a possible disagreement and the reasons in favour of it, nor to the merely heuristic function that a representative of a possible view might have, such as providing formulations and arguments that make the view easier to consider (and therefore to refute). The difference is this: when I consider a merely possible objection to my belief, I am not compelled to adopt the further belief that another person is wrong, but when another person disagrees with my belief, I am compelled to accept that there is a person who is wrong as a corollary to the fact that our beliefs are in conflict with one another

This is what disagreement introduces: my knowledge that a person disagrees with my belief signifies their wrongness. The being in error of another person is signified only by actual disagreement, not by merely possible disagreement, nor by the mere existence of opposing views.

\section{Why Intersubjective Significance Matters}

It is fair to call this significance obvious, but it is not trivial. A circumstance in which you hold a belief that you know someone might possibly take issue with and a circumstance in which that belief brings you into actual conflict with another person are not equivalent. In the case of actual disagreement, your position commits you not only to the belief in that position itself but also to the belief that your opponent is wrong, while in cases of merely possible disagreement your views do not commit you to any similar judgments about another person's epistemic state. 
What is the Epistemic Significance of Disagreement?

As long as your position was justified, the same reasons that support it should have no trouble supporting the weight of its corollaries, so the indication that another person is wrong should not be an occasion for self-doubt. This means that the basic significance I am drawing attention to is not a roundabout way of getting at an indication of likely error, and if the wrongness of another person is indicated, that is not meaningful solely because it indicates that you might be wrong instead.

This raises the question of what difference this significance makes. If disagreement signifies to you that your opponent is wrong, what does that matter? To be specific, what is it about your opponent being wrong that would call for assessment of the epistemic fitness of your opponent, or any other further discussion or investigation? This is the question that brought us here: what calls for assessment of opponents? However, it is not immediately obvious why assessment would be called for by the indication that your opponent was wrong. On the contrary, it seems that this significance would preempt any call for assessment; does it not indicate, on the face of it, that your interlocutor is not your peer, since it indicates that they are wrong?

The basic, intersubjective significance of disagreement is not merely an indirect route to the self-reflexive significance that you should be concerned about the chance that you could be wrong. The wrongness of the other person signifies something about the other person, and that is where its meaning lies. This is to say that the basic significance of disagreement is irreducibly intersubjective. It is the epistemic failure of the other, and not something about my own epistemic state, that disagreement signifies. Further epistemic activity is called for directly by the indication that the other is wrong, and it is called for even if nothing in the intersubjective significance of disagreement ever leads to self-reflexive significance. I will explain why.

Disagreement indicates that the other person is wrong, it does not demonstrate it conclusively. It suggests something in the way that evidence that is not conclusive evidence suggests. It may be univocal, but without being conclusive. As a suggestion, it does not settle the question. Rather, it raises it. It does not demonstrate conclusively that the other is absolutely wrong in their belief, thereby rendering any further inquiry superfluous. Instead, it raises the question of the other's wrongness precisely by indicating that that is the case. It makes perfect sense, then, that this would call for further investigation of the other person, including assessment of their epistemic ability, as long as uncertainty remains about whether what is indicated by the disagreement is true. 


\section{N. Gabriel Martin}

\section{Conclusion}

Despite the interest in the epistemic significance of disagreement in social epistemology, there has not been any attention paid to what the significance of disagreement is. Neglect of this question has led to two problems. For one, it has led to an impossible notion of default peerhood which ignores the necessity (belonging to the very concept of peerhood) that peerhood must be conferred upon assessment. More seriously, it has preserved an excessive narrowness in the way that epistemology of disagreement considers the epistemological meaning of disagreement. This narrowness is by design, and it has beneficially excluded contextual sociological and psychological questions from the narrow scope of the question of what, if anything, is learned about the disputandum from the fact that there is controversy surrounding it.

However, the narrowing of the scope of the question goes too far in considering the epistemic significance of disagreement solely in terms of how and under what circumstances it impinges on your own ability to be reasonably certain. I have argued that, considered strictly epistemologically, the beliefs of others and the correctness of those beliefs are relevant to the epistemic circumstance of the disputandum itself, which is to say to the narrowly determined question of disagreement at issue in social epistemology. It is because of what disagreement tells us about the beliefs of others that it can tell us about the disputandum, in which our primary interest lies. This means that, in order to understand the epistemic significance of disagreement, we cannot exclude what it tells us about the intersubjective context in which our own beliefs exist. ${ }^{26}$

\footnotetext{
${ }^{26}$ Acknowledgements: This paper was presented at the Philosophy Colloquium at the American University of Beirut. Thanks to Tim Carter for comments and copy editing, and to an anonymous referee for comments.
} 